\title{
Child Sexual Abuse Victimization: Focus on Self-Compassion
}

\author{
Christine Wekerle ${ }^{1 *}$, Katherine Kim $^{2}$ and Nikki Wong ${ }^{2}$ \\ ${ }^{1}$ Department of Pediatrics, McMaster University, Hamilton, ON, Canada, ${ }^{2}$ Temerty Faculty of Medicine, University of Toronto, \\ Toronto, ON, Canada
}

Keywords: child welfare, self-compassion, child sexual abuse, child sexual exploitation, Indigenous

\section{INTRODUCTION}

Child sexual abuse (CSA) refers to using a child for the sexual stimulation of an adult, involving contact (touching) or non-contact (not touching) interactions. Where legal age of majority is required for consent, all sexual acts between an adult and underage children, by definition, are CSA. Most U.S. states require investigation into CSA, rather than an alternate child welfare service response (1). In North America, the prevalence of CSA is $20.4 \%$ for girls and $14.1 \%$ for boys, though it is likely much higher than reported due to low rates of disclosure (2). In comparing countries, there is a consensus in terms of contact behaviors, such as fondling and rape (3). Noncontact CSA (i.e., exposure to pornography, verbal sexual harassment, taking sexual photos) is less clearly included in definitions. However, research has shown that non-contact CSA is linked with adolescent distress and poorer quality of life, as compared to no-CSA youth (4). With over 10 years of medical data tracking, substantiated CSA youth were over three times more likely to present with a mental health disorder (e.g., depression, post-traumatic stress disorder, anxiety, behavioral problems, etc.), as compared to the general population. Over $20 \%$ of CSA youth had 2 to 3 diagnoses, and over $22 \%$ had $4+$ diagnoses (5). CSA and psychiatric diagnoses were found to be stronger with self-reported childhood sexual abuse (CSA) than with agency-established CSA (6). While the personal strain to the CSA victim is inestimable, in terms of services and associated costs, the lifetime burden of CSA in the U.S. is placed at $\$ 9.3$ billion (7).

Technically, child sexual exploitation (CSE) is CSA (8). CSE is defined as the involvement of a minor in sexual activity in exchange of something (e.g., money, food, shelter, etc.) from a perpetrator or third-party (e.g., recruiter, trafficker, etc.) (9). Most sex trafficking victims (88.5\% girls) are between 14 and 17 years old. Up to a third of these sex trafficking victims also had reports of CSA and neglect (10). It is important to consider, not only all sexual abuse-related forms (CSE), but also all types of maltreatment $(11,13)$.

Vulnerable youth groups (e.g. gender-diverse, youth of color, Indigenous, refugees) experience systemic CSA risk factors. Youth with histories of greater poly-victimization are more likely to experience maltreatment while in foster care, compared to those with fewer maltreatment experiences (12). CSA in a child welfare system-involved adolescent sample seemed underdetected by caseworkers when considering youth self-report, particularly for boys (13). According to the Canadian Census 2016 data, Indigenous children accounted for $52.2 \%$ of children in foster care, despite only comprising $7.7 \%$ of the child population in Canada, highlighting potential organizational betrayal trauma with multiple care placements $(14,15)$. In a sample of American Indigenous adults with Type 2 diabetes, 29.1\% reported experiencing CSA (16). Youth with CSA backgrounds "cross-over" systems, such as from child welfare to juvenile justice, which may challenge continuity in trauma-informed care (17). Black adolescent girls experience higher rates of sexual violence than girls of other races $[11.2 \%$ forced 
intercourse, (18)], factoring into the CSA to CSE "pipeline" in juvenile justice $(19,20)$. There is evidence for the under-reporting of male CSE victims (21), see ECPAT's Global Boys Initiative (22).

The on-line environment has also been a context for higher CSA risks. Nagata et al. (23) reported youth (aged 12 to 13 years) spend an average of $7.7 \mathrm{~h}$ daily online for entertainment, notably on streaming and gaming platforms. In tracking pandemic impacts, Canada reported a $37 \%$ increase in child luring via a computer, as well as an up to $27 \%$ increase in the production and distribution of child sexual abuse material (CSAM) (24). It is important to appreciate that CSAM represents re-victimization, with image take-downs being difficult to maintain on the surface and dark web. Research shows that CSAM is readily located, with billions of images in circulation (25). In terms of clinical impact, the distinctions among types of CSA are less important than considering these as different aspects of CSA. In this opinion article, we advance that CSA-related trauma and ongoing impairment stems from self-dysfunction, and that selfcompassion as a clinical target is a critical component to traumainformed care.

\section{CSA, POST-TRAUMATIC STRESS AND THE SELF}

Traumatization challenges the development of the self toward a competent identity $(26,27)$. The self-trauma model $(28)$ identifies that early and repeated CSA may disrupt self-schemas and attachment models, as verbal mediation strategies (e.g., self-talk, self-expression) are less available when there is strong classical conditioning (e.g., abuse actions eliciting fear). If there are multiple perpetrators, the one constant is the presence of self; the self and self-emotions (e.g., shame) may come to function as threatening, requiring some perceptual avoidance (29). CSA has been strongly associated with a range of psychological and physical problems in childhood and adulthood, particularly posttraumatic stress disorder (PTSD) (30). PTSD symptomatology specifies three key areas: re-experiencing, avoidance and arousal. Although not without criticism (31), the DSM-5 added two new criteria as part of the new symptom cluster $D$ of negative cognitions and mood: "Persistent, distorted cognitions about the cause or consequences of the traumatic event(s) that lead the individual to blame himself/herself or others" (p. 4), as well as "persistent negative emotional state (e.g., fear, horror, anger, guilt, or shame)" (p. 3). In trauma-exposed foster children, aged 5 to 8 , PTSD diagnosis rates were $54 \%$ of children (32). Among juvenile detainees, CSA predicted PTSD symptoms, over and above other forms of trauma (17), suggesting unique impact of CSA. Lack of safety is salient within an attachment framework for PTSD, with insecure attachment linked with greater PTSD diagnosis and symptoms among children with CSA experiences, compared to those without $(33,34)$. Disrupted mentalizing may underlie self-conceptualization. Mentalization refers to the ability to reflect and understand what one is feeling, as well as the ability to understand others' affective states, which is a process of imagination $(35,36)$. The mentalizing function, with a secure attachment model, would enhance the development of openness, acceptance, curiosity, playfulness, perspective-taking, and selfcompassion. A mentalizing deficit may be a form of inhibition or phobic reaction to mentalizing. In CSA, mentalizing about the self may lag in terms of learning self-compassion from the caregiving environment, with fewer opportunities to practice applying re-appraisal cognitions (positive reframing), or use constructive emotion (loving-kindness) to counteract distress (feeling bad about self) (33). The view of the self may be directly impacted by repeated perpetrator communications (e.g., telling the child "you are nothing"; "you are a slut"; "you want this" etc.), at ages when self-identity is more emergent (under age 8) or more solidified (adolescence to young adulthood). Both are peak ages for CSA (37). Defensive mentalizing (e.g., detachment from emotions), helpful to the survivor in the victimizing environment, may generalize to all emotions, such that positive emotions about the self are more difficult to engage with. Defensive mentalizing could also include restricted emotionality, as with a predominance of fear and anxiety. With post-traumatic stress, triggers for high arousal may trigger anti-mentalizing. As such, self-compassion may be especially challenging to acquire and enact, where a fear of self-compassion may be present.

\section{CSA AND SUICIDALITY}

Stigma and betrayal have been recognized as psychological burdens put upon victims of CSA (38). Adaptation responses may include the development of alexithymia (difficulty in identifying and describing feelings), which has been shown to impact the CSA-suicidality relationship (39). A self-punitiveness model (40) posits that sensitization to negative self-worth leads to an over-generalization of the self as inadequate, preferencing confirmatory experiences, including self-harm. This may serve a short-term function-rigid adherence to being overly self-reliant, maintaining high standards-but a longer-term dysfunction (41). Persistent trauma may be a factor in self-injury and suicidality, in part, related to PTSD symptoms (42) and a trait-level, persistent negative self-concept (40). The most final outcome is the victim's early mortality by suicide (7).

Angelakis et al. (43) and Angelakis et al. (44) found that for suicide attempts (to age 24), the highest rate was for CSA $(O R=3.41)$, and CSA was associated with a 4 -fold increase in having made plans for suicide. In Liu et al.'s (45) review, a medium effect size was found for the relationship of CSA to non-suicidal self-injury. CSA was associated with an over 6-fold increase in repeated self-harm, with CSA being linked with loss and shame (46). Violent victimization is predictive of Indigenous boys' and girls' suicidal ideation and attempts (47), although CSA was not uniquely measured. Increased suicidality among Indigenous youth may reflect, in part, self-colonization with the Indigenous genocidal legacy (48). CSA is directly linked longitudinally to non-suicidal self-harm and suicide attempts among justice system-involved girls (49), and to suicide attempts among adult prisoners [58\% male; (50)]. Early age of CSA onset (before age 9) is linked with increased suicidal intent, particularly with co-occurrence with physical abuse, predicting age at first suicide attempt (51). In a meta-analytic review of 
studies, the population attributable risks for the female and male CSA survivors was found to be about 22\% (females) and $11 \%$ (males) for suicidal behavior (52). In a review of only longitudinal studies of suicidality in youth and young adults, the population attributable risk level was $14.3 \%$ (53). In a large study of child advocacy clinics, 1 in 3 youth reported that they "sometimes want to die" (54). While it has been argued that development is guided by innate self-righting (55), for the CSA youth survivor, maintaining a positive affiliation to the self is a very real issue. PTSD-related anger mediates the CSA-adolescent problem drinking relationship in child welfareinvolved youth (56). Anger may not be evident until social comparison and conceptualizations increase in adolescence (57, 58). Self-harm and suicidality may be, in part, the failure of the meta-cognitive, reflecting functioning, where the adolescent self is understood as having capacity for protective anger and selfcare (59). Supporting self-compassion may re-build mentalizing toward loving-kindness.

\section{SUPPORTING SELF-COMPASSION AND DAMPENING FEAR OF SELF-COMPASSION}

Self-compassion is a malleable protective factor for trauma exposed youth (60). It may be an important therapeutic target for CSA victims with PTSD symptoms (61, 62). Selfcompassion is derived from balance among the emotion regulation systems of threat (sympathetic nervous system) and soothing (parasympathetic nervous system), with various factors impacting motivation to act (63). Self-compassion is conceptualized by Neff and McGehee (64) as reflecting three distinct components: (1) self-kindness (i.e., kindness to oneself in adversity or failure), (2) common humanity (i.e., recognition that one's personal experiences are part of a greater human experience), and (3) mindfulness (i.e., balance of negative thoughts and emotions with awareness and presence). Fear of self-compassion relates to feelings that self-compassion is undeserved, unfamiliar, harmful or unwanted $(65,66)$. Boykin et al. (67) found that females reporting moderate to severe childhood maltreatment endorsed significantly higher levels of fear of self-compassion, as compared with participants with minimal to no childhood maltreatment. Self-compassion may be an important resilience target to address chronic self-issues (i.e., shame), as well as acute distress (i.e., self-hate) (68). Self-compassion may support CSA youth in various problems related to the self, such as body shame, self-efficacy, and selfconcept (69-71). Generally, self-compassion has been positively related to body appreciation, such as protecting women's body appreciation from social comparisons and appearance contingent self-worth (72). In a meta-analytic review of adolescent selfcompassion studies, a large effect size was noted in its impact on reduced distress [i.e., $r=-0.55 ; 95 \% \mathrm{CI}-0.61$ to -0.47 ; (73)]. With regards to child welfare-involved youth, higher selfcompassion was linked with lower depression, problem alcohol use, and suicidality substance (74). Self-compassion has also been shown to have a protective effect against alcohol-related problems in First Nations youth, with Spillane et al. (75) demonstrating a significant positive association between alcohol use and alcohol-related problems among First Nations youth with low self-compassion levels. However, Miron et al. (76) found a significant indirect effect of CSA on PTSD via fear of selfcompassion, rather than self-compassion. Self-compassion may counter an overactive threat system and avoidant responses to high arousal. Adopting a self-compassionate stance is associated with less shame $(77,78)$ and decreased self-criticism (79, 80 ). For adolescents who, developmentally, are highly engaged with socially-prescribed self-identity, social self-compassion (e.g., managing social blunders, failing to meet social expectations) may be especially relevant (41).

Self-compassion resonates in various Indigenous cultures. For example, Haudenosaunee perspectives include kindness and gratitude as part of the concept of "good mind," which is more communally defined in terms of the power of the mind that is unified amongst relatives than individually-focused (81). The Mohawk word for compassion translates as "love among us" (A. General, personal communication, November 16, 2021). The Haudenosaunee perspective of self-compassion is self-love as a gifted creation. The Great Law of Peace directs balancing the principles of compassion for relations and the strength of self-love. In one sample of American Indigenous people, self-compassion enhanced one's feeling of belongingness, thus allowing for a better connection with community (82). Selfcompassion was also associated with a decreased suicide risk in American Indigenous-identifying individuals (82).

Recent factor analytic work suggests refinement on how to view self-compassion components. In testing the factor structure of self-compassion, Strickland et al. (83) showed that, in a collegiate sample, a total score was not indicated. Instead, a two-factor higher-order model, with six lower-order factors best described the data. These two factors were labeled as self-caring and self-coldness. The lower-order factors for selfcaring were: self-kindness, mindfulness, and common humanity. Lower-order factors for self-coldness were: self-judgment, overidentification, and isolation. Presumably, activating self-caring would be protective for managing self-coldness; self-coldness would be an intervention target to address punitiveness. The fear of self-compassion seems to represent two factors, one related to internalized social standards (i.e., flaws, failings), and one related to "emergency" emotionality (i.e., vulnerability, grief) (84). CSA may alter the view of the "self-in-the-world" as highly vulnerable, where self-compassion is not warranted or very contradictory to the self-schema. Fear of self and fear of selfcompassion may relate to the lack of a protective presence in the overall experience of the CSA victim. Factor analytic studies on both self-compassion and fear of self-compassion scales show a commonality of the self-fears.

In reviewing self-compassion, PTSD and trauma, Winders et al. (85) included 35 studies where the mean age was 18 years old, with 11 of these being self-compassion intervention studies. Most self-compassion intervention studies showed improvements in PTSD symptoms and trauma-related guilt and shame; however, adolescents with CSA histories were not specifically considered in comparison to non-CSA youth. CSA 
interventions may include an emotion-focused therapy approach where protective anger helps to motivate self-protective, adaptive action (86). A meta-analysis of self-compassion interventions revealed significant improvement compared to controls in the following outcomes: self-compassion, stress, depression, mindfulness, self-criticism, and anxiety. Among these, depression symptoms improved and self-compassion was maintained over follow-up (87). While the differing impacts of intervention types were not analyzed, the types of interventions included both group and individual approaches referring to selfcompassion theory. Recently, this approach has been combined with self-compassion training in an on-line program delivery model (88). Halamová et al. (88)'s on-line program, Emotion Focused Training for Self-Compassion and Self-Protection found improvements in both self-compassion and self-hatred among a general community sample, recruited through social media sites and health forums (control group mean age of 25.35 years; intervention group mean age of 33.73 years). Self-compassion has also been implemented in the mental health app, JoyPopTM, which includes a journal feature with writing prompts on the topic of self-compassion (e.g., "You should talk to yourself like someone you love. What are some qualities that you love about yourself?"). The app as a whole encourages a positive and kind view of the self, which can be replicated in other interventions (89). Interventions designed to develop a resilient self that address both the bolstering of self-compassion and the reduction of fear of self-compassion may be meritorious for those with CSA experiences, especially youth with intersectional traumas.

\section{CONCLUSION}

There is a clear global consensus for the illegality and wrong of CSA, how it is an infringement of child rights in the highest order, and how CSA, CSE, and CSAM prevention is a high value, coordinated target for public health. The increasing trends in CSAM is a warning call to invest strongly in prevention, early intervention, and developmentally timed intervention. Adolescence is a key timeframe for self-identity and is a time of high on-line engagement; it is critical for youth to grow in emerging adulthood in safe, supportive environments, and practice adaptive emotion regulation skills. A population study of youth with and without substantiated CSA showed that CSA and substance misuse are significantly associated with the age at

\section{REFERENCES}

1. U.S. Department of Health and Human Services, Administration for Children and Families, Administration on Children, Youth and Families, Children's Bureau. Child Maltreatment 2020. (2021). Available online at: https://www.acf. hhs.gov/sites/default/files/documents/cb/cm2020.pdf (accessed November 19, 2021).

2. Moody G, Cannings-John R, Hood K, Kemp A, Robling M. Establishing the international prevalence of self-reported child maltreatment: A systematic review by maltreatment type and gender. BMC Public Health. (2018) 18:1-15. doi: 10.1186/s12889-0186044-y onset of psychotic disorders (90). Traub and Boynton-Jarrett (91) specify modifiable factors to bolster resilience, including fostering positive appraisal styles and self-care skills. We would add selfcompassion to this listing of therapeutic strategies for effortful regulation of the self and consider self-compassion interventions (tackling also fear of self-compassion) as a good-fit model for addressing CSA-related impact. Anticipatory guidance and our duty-to-care propels greater empirically-based innovations that consider self-compassion in supporting CSA victims, from detection and disclosure to post-traumatic growth. It seems imperative that full measurement of self-compassion, including fear of self-compassion, is built into measurement models for intervention research, and that diverse populations, including those at higher risk of CSA, are included in studies. Studies on fear of self-compassion interventions are notably limited and a research gap to be filled. Coherent work is needed to evaluate its potential good fit for youth with CSA experiences. CSA is an experience put upon youth who are protected from this in law, yet whose very conceptualization of themselves and their feelings is jeopardized and whose capacity to survive and thrive is undermined. Preventing suicidality directs toward prevention of CSA, CSE and CSAM. Trauma-informed care prioritizes client psychological safety and trauma research needs to invest in understanding the potential of self-compassion interventions for our young people.

\section{AUTHOR CONTRIBUTIONS}

CW contributed to the majority of the writing and research. KK and NW supported in the writing and research. All authors edited and revised. All authors contributed to the article and approved the submitted version.

\section{FUNDING}

This work was funded by the Canadian Institutes of Health Research Indigenous Gender and Wellness Grant number IWD171382 .

\section{ACKNOWLEDGMENTS}

We would like to acknowledge Sehyun Shannon Oh for her research support.
3. Dubowitz H. Child sexual abuse and exploitation - A global glimpse. Child Abuse Neglect. (2017) 66:2-8. doi: 10.1016/j.chiabu.2017.02.011

4. Mohler-Kuo M, Landolt MA, Maier T, Meidert U, Schönbucher V, Schnyder U. Child sexual abuse revisited: a population-based cross-sectional study among Swiss adolescents. Journal of Adolescent Health. (2014) 54:30411. doi: $10.1016 /$ j.jadohealth.2013.08.020

5. Alie-Poirier A, Hébert M, McDuff P, Daigneault I. Mental health profiles of sexually abused youth: comorbidity, resilience and complex PTSD. Int J Child Adolesc Resilience. (2020) 7:123-38. doi: 10.7202/1072593ar

6. Mills R, Kisely S, Alati R, Strathearn L, Najman J. Self-reported and agencynotified child sexual abuse in a population-based birth cohort. J Psychiatr Res. (2016) 74:87-93. doi: 10.1016/j.jpsychires.2015.12.021 
7. Letourneau EJ, Brown DS, Fang X, Hassan A, Mercy JA. The economic burden of child sexual abuse in the United States. Child Abuse Neglect. (2018) 79:413-22. doi: 10.1016/j.chiabu.2018.02.020

8. Murray LK, Nguyen A, Cohen JA. Child sexual abuse. Child Adolesc Psychiatr Clin. (2014) 23:321-37. doi: 10.1016/j.chc.2014.01.003

9. Interagency Working Group on Sexual Exploitation of Children. Terminology Guidelines for the Protection of Children from Sexual Exploitation and Sexual Abuse. (2016). Available online at: https://www.ohchr.org/Documents/Issues/ Children/SR/TerminologyGuidelines_en.pdf (accessed November 19, 2021).

10. U.S. Department of Health and Human Services, Administration for Children and Families, Administration on Children, Youth and Families, Children's Bureau. Child Maltreatment 2019. (2021). Available online at: www.acf.hhs.gov/cb/research-data-technology/statistics-research/ child-maltreatment (accessed November 19, 2021).

11. Steine IM, Nielsen B, Porter PA, Krystal JH, Winje D, Grønli J, et al. Predictors and correlates of lifetime and persistent non-suicidal self-injury and suicide attempts among adult survivors of childhood sexual abuse. Eur J Psychotraumatol. (2020) 11:1815282. doi: 10.1080/20008198.2020.1815282

12. Katz CC, Courtney ME, Novotny E. Pre-foster care maltreatment class as a predictor of maltreatment in foster care. Child Adoles Soc Work J. (2017) 34:35-49. doi: 10.1007/s10560-016-0476-y

13. Wekerle C, Goldstein AL, Tanaka M, Tonmyr L. Childhood sexual abuse, sexual motives, and adolescent sexual risk-taking among males and females receiving child welfare services. Child Abuse Neglect. (2017) 66:10111. doi: 10.1016/j.chiabu.2017.01.013

14. Smidt AM, Freyd JJ. Government-mandated institutional betrayal. J Trauma Dissociation. (2018) 19:491-9. doi: 10.1080/15299732.2018.1502029

15. Indigenous Services Canada, Social Programs, First Nations Child and Family Services. Reducing the Number of Indigenous Children in Care. Available online at: https://www.sac-isc.gc.ca/eng/1541187352297/1541187392851 (accessed November 19, 2021).

16. Elma JH, Hautalab D, Abrahamson-Richardsa T, Wallsb ML. Patterns of adverse childhood experiences and mental health outcomes among American Indians with type 2 diabetes. Child Abuse Negl. (2021) 122:105326. doi: 10.1016/j.chiabu.2021.105326

17. Chaplo SD, Kerig PK, Bennett DC, Modrowski CA. The roles of emotion dysregulation and dissociation in the association between sexual abuse and self-injury among juvenile justice-involved youth. J Trauma Dissoc. (2015) 16:272-85. doi: 10.1080/15299732.2015.989647

18. Thompson NJ, McGee RE, Mays D. Race, Ethnicity, substance use, and unwanted sexual intercourse among adolescent females in the United States. West J Emerg Med. (2012) 13:283-8. doi: 10.5811/westjem.2012.3.11774

19. Kerig PK. Polyvictimization and girls' involvement in the juvenile justice system: Investigating gender-differentiated patterns of risk, recidivism, and resilience. J Interpers Violence. (2018) 33:789-809. doi: 10.1177/0886260517744843

20. Saar MS, Epstein R, Rosenthal L, Vafa Y. The Sexual Abuse to Prison Pipeline: The Girls' Story. Human Rights Project for Girls. Georgetown Law Center on Poverty and Inequality, \& Ms. Foundation for Women. (2015). Available online at: https://www.law.georgetown.edu/poverty-inequality-center/wpcontent/uploads/sites/14/2019/02/The-Sexual-Abuse-To-Prison-PipelineThe-Girls\%E2\%80\%99-Story.pdf (accessed November 19, 2021).

21. Josenhans V, Kavenagh M, Smith S, Wekerle C. Gender, rights and responsibilities: the need for a global analysis of the sexual exploitation of boys. Child Abuse Neglect. (2020) 110:104291. doi: 10.1016/j.chiabu.2019.104291

22. ECPAT International. Global Boys Initiative: A Global Review of Existing Literature on the Sexual Exploitation of Boys. Sexual Exploitation of Boys. (2021). Available from https://ecpat.org/wp-content/uploads/2021/09/ Global-Boys-Initiative-Literature-Review-ECPAT-International-2021.pdf (accessed November 19, 2021).

23. Nagata JM, Cortez CA, Cattle CJ, Ganson KT, Iyer P, Bibbins-Domingo K, et al. Screen Time Use Among US Adolescents During the COVID-19 Pandemic: Findings From the Adolescent Brain Cognitive Development (ABCD) Study. JAMA Pediatr. (2021) 176:94-6. doi: 10.1001/jamapediatrics.2021.4334

24. Statistics Canada. (2021). Statistics Canada's Police-Reported Crime Data 2020 Statistics. Available online at: https://www150.statcan.gc.ca/n1/dailyquotidien/210727/dq210727a-eng.htm (accessed November 19, 2021).
25. Guerra E, Westlake BG. Detecting child sexual abuse images: traits of child sexual exploitation hosting and displaying websites. Child Abuse Negl. (2021) 122:105336. doi: 10.1016/j.chiabu.2021.105336

26. Penner F, Gambin M, Sharp C. Childhood maltreatment and identity diffusion among inpatient adolescents: the role of reflective function. J Adolesc. (2019) 76:65-74. doi: 10.1016/j.adolescence.2019.08.002

27. Dereboy F, Dereboy C, Eskin M. Validation of the DSM-5 alternative model personality disorder diagnoses in Turkey, Part 1: LEAD validity and reliability of the personality functioning ratings. J Pers Assess. (2018) 100:60311. doi: 10.1080/00223891.2018.1423989

28. Briere J. The APSAC Handbook on Child Maltreatment. 2nd ed. Newbury Park, CA: Sage Publications (2002).

29. Ehlers A, Clark DM. A cognitive model of posttraumatic stress disorder. Behav Res Therapy. (2000) 38:319-45. doi: 10.1016/S0005-7967(99)00123-0

30. Maalouf O, Daigneault I, Dargan S, McDuff P, Frappier JY. Relationship between child sexual abuse, psychiatric disorders and infectious diseases: a matched-cohort study. J Child Sex Abus. (2020) 29:749-68. doi: 10.1080/10538712.2019.1709242

31. Pai A, Suris AM, North CS. Posttraumatic stress disorder in the DSM5: controversy, change, and conceptual considerations. Behav Sci. (2017) 7:1-7. doi: 10.3390/bs7010007

32. Hitchcock C, Goodall B, Sharples O, Meiser-Stedman R, Watson P, Ford $\mathrm{T}$, et al. Population prevalence of the posttraumatic stress disorder subtype for young children in Nationwide Surveys of the British General Population and of Children in Care. J Am Acad Child Adolesc Psychiatry. 60:127887.e3. doi: 10.1016/j.jaac.2020.12.036

33. Ensink K, Fonagy P, Normandin L, Rozenberg A, Marquez C, Godbout N, et al. Post-traumatic stress disorder in sexually abused children: secure attachment as a protective factor. Front Psychol. (2021) 12:646680. doi: 10.3389/fpsyg.2021.646680

34. Jardin C, Venta A, Newlin E, Ibarra S, Sharp C. Secure attachment moderates the relation of sexual trauma with trauma symptoms among adolescents from an inpatient psychiatric facility. J Interpers Violence. (2017) 32:156585. doi: $10.1177 / 0886260515589928$

35. Allen JG, Fonagy P, Bateman AW. Mentalizing in Clinical Practice. Washington, DC: American Psychiatric Pub. (2008).

36. Fonagy P, Steele M, Steele H, Moran GS, Higgitt AC. The capacity for understanding mental states: The reflective self in parent and child and its significance for security of attachment. Infant Ment Health J. (1991) 12: 201-18. doi: 10.1002/1097-0355(199123)12:3\&lt;201::AIDIMHJ2280120307\&gt;3.0.CO;2-7

37. Cammack AL, Hogue CJ. Retrospectively self-reported age of childhood abuse onset in a United States nationally representative sample. Inj Epidemiol. (2017) 4:7. doi: 10.1186/s40621-017-0103-1

38. Finkelhor D, Browne A. The traumatic impact of child sexual abuse: a conceptualization. Am J Orthopsychiatry. (1985) 55:53041. doi: 10.1111/j.1939-0025.1985.tb02703.x

39. Liu H, Wang W, Yang J, Guo F, Yin Z. The effects of alexithymia, experiential avoidance, and childhood sexual abuse on non-suicidal self-injury and suicidal ideation among Chinese college students with a history of childhood sexual abuse. J Affect Disord. (2021) 282:272-9. doi: 10.1016/j.jad.2020.12.181

40. Flett GL, Goldstein AL, Hewitt PL, Wekerle C. Predictors of deliberate self-harm behavior among emerging adolescents: an initial test of a self-punitiveness model. Curr Psychol. (2012) 31:49-64. doi: 10.1007/s12144-012-9130-9

41. Flett GL, Flett AL, Wekerle C. A Conceptual analysis of interpersonal resilience as a key resilience domain: understanding the ability to overcome child sexual abuse and other adverse interpersonal contexts. Int J Child Adolesc Resilience. (2015) 3:4-33. Available online at: https://www.ijcar-rirea.ca/index. php/ijcar-rirea/article/view/173

42. Modrowski CA, Mendez L, Kerig PK. Associations among trauma exposure, posttraumatic dissociation, reckless/self-destructive behavior, and adolescent offending. J Trauma Dissoc. (2021) 22:487-501. doi: 10.1080/15299732.2020.1869655

43. Angelakis I, Austin JL, Gooding P. Association of childhood maltreatment with suicide behaviors among young people: a systematic review and meta-analysis. JAMA Netw Open. (2020) 3:e2012563. doi: 10.1001/jamanetworkopen.2020.12563 
44. Angelakis I, Austin JL, Gooding P. Childhood maltreatment and suicide attempts in prisoners: a systematic meta-analytic review. Psychol Med. (2020) 50:1-10. doi: 10.1017/S0033291719002848

45. Liu RT, Scopelliti KM, Pittman SK, Zamora AS. Childhood maltreatment and non-suicidal self-injury: a systematic review and meta-analysis. Lancet Psychiatry. (2018) 5:51-64. doi: 10.1016/S2215-0366(17)30469-8

46. Troya MI, Dikomitis L, Babatunde OO, Bartlam B, Chew-Graham CA. Understanding self-harm in older adults: a qualitative study. EClinicalMedicine. (2019) 12:52-61. doi: 10.1016/j.eclinm.2019. 06.002

47. Manzo K, Hobbs GR, Gachupin FC, Stewart J, Knox SS. Reservation-urban comparison of suicidal ideation/planning and attempts in American Indian Youth. J Sch Health. (2020) 90:439-46. doi: 10.1111/josh.12891

48. Aho K, Liu J. Indigenous suicide and colonization: the legacy of violence and the necessity of self-determination. Int J Conf Violence. (2010) 4:124-133. doi: $10.4119 / \mathrm{ijcv}-2819$

49. Rabinovitch SM, Kerr DC, Leve LD, Chamberlain P. Suicidal Behavior Outcomes of Childhood Sexual Abuse: Longitudinal Study of Adjudicated Girls. Suicide Life Threat Behav. (2015) 45:431-47. doi: 10.1111/sltb.12141

50. Angelakis I, Gillespie EL, Panagioti M. Childhood maltreatment and adult suicidality: a comprehensive systematic review with meta-analysis. Psychol Med. (2019) 49:1057-78. doi: 10.1017/S0033291718003823

51. Lopez-Castroman J, Melhem N, Birmaher B, Greenhill L, Kolko D, Stanley B, et al. Early childhood sexual abuse increases suicidal intent. World psychiatry. (2013) 12:149-54. doi: 10.1002/wps.20039

52. Devries KM, Mak JY, Child JC, Falder G, Bacchus LJ, Astbury J, et al. Childhood sexual abuse and suicidal behavior: a meta-analysis. Pediatrics. (2014) 133:e1331-44. doi: 10.1542/peds.2013-2166

53. Castellví P, Miranda-Mendizábal A, Parés-Badell O, Almenara J, Alonso I, Blasco MJ, et al. Exposure to violence, a risk for suicide in youths and young adults. A meta-analysis of longitudinal studies. Acta Psychiatr Scand. (2016) 135:195-211. doi: 10.1111/acps.12679

54. Bernard-Bonnin AC, Hébert M, Allard-Dansereau C, GauthierDuchesne A. Suicidal ideations among sexually abused children: a critical need for better understanding. Paediatr Child Health. (2017) 22:e3. doi: 10.1093/pch/pxx086.007

55. Masten A, Best K, Garmezy N. Resilience and development: contributions from the study of children who overcome adversity. Dev Psychopathol. (1990) 2:425-44. doi: 10.1017/S0954579400005812

56. Hudson A, Wekerle C, Goldstein AL, et al. Gender differences in emotionmediated pathways from childhood sexual abuse to problem drinking in adolescents in the child welfare system. J Child Adolesc Trauma. (2017) 10:19-28. doi: 10.1007/s40653-016-0125-9

57. Thomas SP, Bannister SC, Hall JM. Anger in the trajectory of healing from childhood maltreatment. Arch Psychiatr Nurs. (2012) 26:169-80. doi: 10.1016/j.apnu.2011.09.003

58. Walker HE, Wamser-Nanney R, Howell KH. Child sexual abuse and adult sexual assault among emerging adults: exploring the roles of posttraumatic stress symptoms, emotion regulation, and anger. J Child Sex Abus. (2021) 30:407-26. doi: 10.1080/10538712.2021.1890295

59. Borelli JL, Brugnera A, Zarbo C, Rabboni M, Bondi E, Tasca GA, et al. Attachment comes of age: adolescents' narrative coherence and reflective functioning predict well-being in emerging adulthood. Attach Hum Dev. (2019) 21:332-51. doi: 10.1080/14616734.2018.1479870

60. Zeller M, Yuval K, Nitzan-Assayag Y, Bernstein A. Self-compassion in recovery following potentially traumatic stress: longitudinal study of at-risk youth. J Abnorm Child Psychol. (2015) 43:64553. doi: 10.1007/s10802-014-9937-y

61. Bluth K, Roberson PN, Gaylord SA, Faurot KR, Grewen KM, Arzon S., et al. Does Self-compassion Protect Adolescents from Stress? J Child Fam Stud. (2016) 25:1098-1109. doi: 10.1007/s10826-015-0307-3

62. Thompson BL, Waltz J. Self-compassion and PTSD symptom severity. $J$ Trauma Stress. (2008) 21:556-8. doi: 10.1002/jts.20374

63. Gilbert P. The Compassionate Mind: A New Approach to Life's Challenges. London: Constable \& Robinson (2009).

64. Neff K, McGehee P. Self-compassion and psychological resilience among adolescents and young adults. Self Identity. (2010) 9:225-240. doi: 10.1080/15298860902979307
65. Gilbert P, McEwan K, Matos M, Rivis A. Fears of compassion development of three self-report measures. Psychol Psychother. (2011) 84:239-55. doi: 10.1348/147608310X526511

66. Gilbert P, McEwan K, Gibbons L, Chotai S, Duarte J, Matos M. Fears of compassion and happiness in relation to alexithymia, mindfulness, and self-criticism. Psychol Psychother. (2012) 85:374-90. doi: 10.1111/j.2044-8341.2011.02046.x

67. Boykin DM, Himmerich SJ, Pinciotti CM, Miller LM, Miron LR, Orcutt HK. Barriers to self-compassion for female survivors of childhood maltreatment: the roles of fear of self-compassion and psychological inflexibility. Child Abuse Negl. (2018) 76:216-24. doi: 10.1016/j.chiabu.2017.11.003

68. Gilbert P, Procter S. Compassionate mind training for people with high shame and self-criticism: overview and pilot study of a group therapy approach. Clin Psychol Psychother. (2006) 13:353-79. doi: 10.1002/cpp.507

69. MacGinley M, Breckenridge J, Mowll J. A scoping review of adult survivors experiences of shame following sexual abuse in childhood. Health Soc Care Community. (2019) 27:1135-46. doi: 10.1111/hsc.12771

70. Guerra C, Farkas C, Moncada L. Depression, anxiety and PTSD in sexually abused adolescents: association with self-efficacy, coping and family support. Child Abuse Negl. (2018) 76:310-20. doi: 10.1016/j.chiabu.2017.11.013

71. Gewirtz-Meydan A. The relationship between child sexual abuse, self-concept and psychopathology: the moderating role of social support and perceived parental quality. Child Youth Serv Rev. (2020) 113:104938. doi: 10.1016/j.childyouth.2020.104938

72. Homan KJ, Tylka TL. Self-compassion moderates body comparison and appearance self-worth's inverse relationships with body appreciation. Body Image. (2015) 15:s1-7. doi: 10.1016/j.bodyim.2015.04.007

73. Marsh IC, Chan S, MacBeth A. Self-compassion and Psychological Distress in Adolescents-a Meta-analysis. Mindfulness. (2018) 9:101127. doi: 10.1007/s12671-017-0850-7

74. Tanaka M, Wekerle C, Schmuck ML, Paglia-Boak A, MAP Research Team. The linkages among childhood maltreatment, adolescent mental health, and self-compassion in child welfare adolescents. Child Abuse Neglect. (2011) 35:887-98. doi: 10.1016/j.chiabu.2011.07.003

75. Spillane NS, Schick MR, Goldstein SC, Nalven T, Kahler CW The protective effects of self-compassion on alcohol-related problems among first nation adolescents. Addict Res Theory. (2021) 30:33-40. doi: 10.1080/16066359.2021.1902994

76. Miron LR, Seligowski AV, Boykin DM, Orcutt HK. The potential indirect effect of childhood abuse on posttrauma pathology through self-compassion and fear of self-compassion. Mindfulness. (2016) 7:596605. doi: 10.1007/s12671-016-0493-0

77. Johnson EA, O'Brien KA. Self-compassion soothes the savage ego-threat system: Effects on negative affect, shame, rumination, and depressive symptoms. J Soc Clin Psychol. (2013) 32:93963. doi: 10.1521 /jscp.2013.32.9.939

78. Woods H, Proeve M. Relationships of mindfulness, self-compassion, and meditation experience with shame-proneness. J Cogn Psychother. (2014) 28:20-33. doi: 10.1891/0889-8391.28.1.20

79. Hiraoka R, Meyer EC, Kimbrel NA, DeBeer BB, Gulliver SB, Morissette SB. Self-compassion as a prospective predictor of PTSD symptom severity among trauma-exposed US Iraq and Afghanistan war veterans. J Trauma Stress. (2015) 28:127-33. doi: 10.1002/jts.21995

80. Hoffart A, Øktedalen T, Langkaas TF. Self-compassion influences PTSD symptoms in the process of change in trauma-focused cognitive-behavioral therapies: a study of within-person processes. Front Psychol. (2015) 6:1273. doi: 10.3389/fpsyg.2015.01273

81. Noronha N, Smith SJ, Martin Hill D, Davis Hill L, Smith S, General A, et al. The Use of mobile applications to support indigenous youth wellbeing in Canada. Int J Child Adolesc Resilience. (2021) 8:12434. doi: 10.7202/1077724ar

82. Dolezal S, Winterowd C, Farra A. The relationship of selfcompassion and suicide risk factors in American Indian/Alaska Native people. Am Indian Alaska Native Ment Health Res J. (2021) 28:103-24. doi: 10.5820/aian.2801.2021.103

83. Strickland NJ, Nogueira-Arjona R, Mackinnon S, Wekerle C, Stewart SH. Clarifying the factor structure of the self-compassion scale. Eur J Psychol Assess. (2021) 1-16. doi: 10.1027/1015-5759/a000672 
84. Geller J, Iyar MM, Kelly AC, Srikameswaran S. Barriers to self-compassion in the eating disorders: The factor structure of the fear of selfcompassion scale. Eat Behav. (2019) 35:101334. doi: 10.1016/j.eatbeh.2019. 101334

85. Winders SJ, Murphy O, Looney K, O’Reilly G. Self-compassion, trauma, and posttraumatic stress disorder: a systematic review. Clin Psychol Psychother. (2020) 27:300-29. doi: 10.1002/cpp.2429

86. Timulak L, Pascual-Leone A. New developments for case conceptualization in emotion-focused therapy. Clin Psychol Psychother. (2014) 22:61936. doi: $10.1002 /$ cpp. 1922

87. Ferrari M, Hunt C, Harrysunker A, Abbott MJ, Beath AP, Einstein DA. Self-compassion interventions and psychosocial outcomes: A metaanalysis of RCTs. Mindfulness. (2019) 10:1455-73. doi: 10.1007/s12671-01901134-6

88. Halamová J, Kanovský M, Varšová K, Kupeli N. Randomised controlled trial of the new short-term online emotion focused training for self-compassion and self-protection in a nonclinical sample. Curr Psychol. (2021) 40:33343. doi: 10.1007/s12144-018-9933-4

89. MacIsaac A, Mushquash AR, Mohammed S, Grassia E, Smith S, Wekerle C. Adverse childhood experiences and building resilience with the joypop app: evaluation study. JMIR mHealth uHealth. (2021) 9:e25087. doi: 10.2196/ 25087

90. Bourgeois C, Lecomte T, McDuff P, Daigneault I. Child sexual abuse and age at onset of psychotic disorders: a matched-cohort study: L'âge d'apparition des troubles psychotiques chez les victimes d'agression sexuelle à l'enfance: Une étude prospective de cohortes appariées. Canad J Psychiatry. (2021) 66:569-76. doi: 10.1177/0706743720970853

91. Traub F, Boynton-Jarrett R. Modifiable resilience factors to childhood adversity for clinical pediatric practice. Pediatrics. (2017) 139:e20162569. doi: 10.1542/peds.2016-2569

Conflict of Interest: The authors declare that the research was conducted in the absence of any commercial or financial relationships that could be construed as a potential conflict of interest.

Publisher's Note: All claims expressed in this article are solely those of the authors and do not necessarily represent those of their affiliated organizations, or those of the publisher, the editors and the reviewers. Any product that may be evaluated in this article, or claim that may be made by its manufacturer, is not guaranteed or endorsed by the publisher.

Copyright (c) 2022 Wekerle, Kim and Wong. This is an open-access article distributed under the terms of the Creative Commons Attribution License (CC BY). The use, distribution or reproduction in other forums is permitted, provided the original author(s) and the copyright owner(s) are credited and that the original publication in this journal is cited, in accordance with accepted academic practice. No use, distribution or reproduction is permitted which does not comply with these terms. 